\title{
Multi Criteria Water Allocation Modelling to Demonstrate the Need of a Comprehensive Water Policy for Sri Lanka
}

\author{
N.T.S. Wijesekera
}

\begin{abstract}
In Sri Lanka, over 30 national institutions compete to obtain access and priority to use water to perform a variety of water service delivery functions. Water sharing problems have created many conflicts among stakeholders. Presently, there is a lack of transparent and verified models for the assessment of water availability, demand and perform water allocation. It appears that the current practice based on weak information combined with stakeholder judgement is considered as acceptable mainly because of the absence of a water policy and regulatory system. The objective of the present work is to perform a multi criteria assessment to compare the priority of water allocation based on the judgement of water experts and then to evaluate the adequacy of same to evaluate the need to establish a comprehensive water policy. Five multi criteria modelling options based on stakeholder perceptions from 11 water user institutions were compared with the order of magnitude of present water use. Available water was first prioritised using the model weights and then reallocated to the three top ranked water users by considering their annual water use. Multi criteria water allocation models with consistent parameters could be developed by using stakeholder perceptions and rational assumptions. Comparative evaluation of model outputs and the order of magnitude water use data showed that any attempts to use stakeholder consultation with water allocation models must be well supported with transparent and verified water availability and demand assessments. Demonstrating that water allocation based on stakeholder opinion alone is not satisfactory, the present work points to the urgent need for Sri Lanka to seek a comprehensive water policy, rules and regulations.
\end{abstract}

Keywords: Analytical Hierarchy Process, Modelling, Water resources, Demand assessment, Verification, Stakeholder

\section{Introduction}

\subsection{The Setting}

In Sri Lanka, water is a limited resource and many institutions and sectors are competing to obtain access and priority to use. Over 30 national institutions perform the implementation of various water services as irrigation, drinking water supply, drainage, sanitation, hydropower generation, environmental protection, education, research, and policy formulation. These institutions which involve in performing many service delivery functions experience difficulties when obtaining access to water resources because of overlapping functions and uncertain legislations. Out of a large number of state institutions dealing with water, there are many organisations executing multiple water sector activities while several are confined to only one major water sector activity. This aspect is shown in a publication by Samad et al. in 2017 [1], by showing a comparison of institutional involvement in five sub sectors of water. The institutions that deal with multiple water tasks are administratively well established and they take care of tasks based on spatial distribution and magnitude of each sub sector that had been entrusted to them. The Mahaweli system of Sri Lanka comprises a number of administrative districts with a hydraulically inter-linked system of reservoirs used for multiple uses and managed by different agencies.

At present, the 'safe' drinking water coverage in the country is around 86 percent of the population while the population having pipe borne water supply facilities is around 46 percent. Currently, around 35.2 percent of the population is connected to the national pipe borne water distribution network of the National Water Supply \& Drainage Board (NWSDB) and 10.8 percent of the population is served pipe borne water facilities through

Eng. (Prof.) N.T.S.Wijesekera, C. Eng., FIE (Sri Lanka), MICE(UK), B.Sc. Eng. (Sri Lanka), PG Dip Hyd. Structures (Moratuwa), M. Eng. (Tokyo), D. Eng. (Tokyo). Senior Professor of Civil Engineering, Department of Civil Engineering, University of Moratuwa, Sri Lanka.

Email:sohanw2@gmail.com

ORCID ID: http://orcid.org/0000-0003-0964-4331 
Community Based Organisations (CBOs) [2]. Hence the NWSDB and the Department of Community Water Supply also urge a priority access for the available water resources. Due to the importance of the responsibilities assigned to such agencies, it is necessary to distribute the limited water resources among these stakeholders by ensuring the best services to the public. This necessitates a well cocoordinated mechanism for management, by keeping in line with the water allocation practices in the system. There are few administratively formed bodies such as the Water Panel, and the Integrated Management of Irrigation Settlements (INMAS) [3] to develop water management plans. It could be noted that these systems are limited to selected locations in the country. It is stated that according to powers vested by the Mahaweli Authority of Sri Lanka Act 23 of Sri Lanka [4], the "Water Management Panel" and the "Water Management Secretariat" had been established to coordinate water users in the areas of its jurisdiction. As at present, the only mechanism for multi-stakeholder water allocation at national level in Sri Lanka is this water panel which coordinates the Ceylon Electricity Board (CEB), Water Board, Department of Irrigation (ID), and Meteorology Department [5].

\subsection{The Problem}

The competition for water has resulted in many conflicts [1] that had attracted the attention of the government. Among the most talked about conflicts are, the water sharing problems at Muruthawela, Thuruwila [6]-[8], Rajanganaya [9], [10], Wahalkada and Mahakandarawa [11], and Iranamadu [8], [12], [13] reservoirs which are spread across the entire island. The above cited publications on these conflicts highlight the lack of transparent resource assessment and allocation policies, methods and practices for rational water allocation. Such documents are very important to build the confidence of water users and general public. There is a need to develop and publish a government accepted water resources and associated infrastructure assessment, planning, design and management guideline supported with a national policy and appropriate implementation institutions. The study of political and institutional context of the water sector in Sri Lanka conducted in 2017 also highlights the need for a sound water policy [1]. It is also very important for Sri Lanka to possess accepted methods and practice guidelines for water assessments and management to support a good water policy. Hence, the documentation used by the Department of Irrigation [14], Mahaweli Authority model [15], and practices of other sector institutions for water resources planning, engineering and management, must be reviewed and published with sufficient technical details in order to ensure the transparency of water assessment and management for acceptable water allocation.

Though the attempts to develop a water policy and associated documentation for Sri Lanka commenced in 1993 with ADB assistance [16], [17], such efforts had been abandoned due to reasons that had not been officially disclosed. This may be due to either the political will, power struggle between user institutions or both. However, there are a few subsequent efforts which are yet to bear fruit, [18]. The lack of a water policy and supporting management systems to rationally allocate and deal with water has created many water sharing problems.

\section{The Objective}

One way to expedite the process leading to a comprehensive water policy, rules and regulations is to convince the water managers that understanding, experience and judgement must be supplemented with sound information to arrive at rational water allocation decisions. In literature related to water allocation in Sri Lanka, there is a gap in the availability of systematic work to demonstrate how difficult it would be for water managers to decide on water allocation priority by considering only the understanding, experience and judgement. Therefore, the objective of the present study was to carry out a multi criteria assessment to compare the priority of water allocation based on the understanding, experience and judgement of water experts from 20 water user organisations of Sri Lanka and then to evaluate the adequacy for acceptable water management.

\section{$2.1 \quad$ Task Outline}

Achieving the study objective required an evaluation with an appropriate set of water experts. Hence the present work targeted an evaluation of priority weights for water users, that would be assigned only with the use of knowledge, experience, and judgement of decision making stakeholders. 
Hence a workshop with the participation of Sri Lanka's leading water stakeholders was conducted to discuss the current situation and the need to have a systematic approach towards rational water allocation. Out of 20 leading water sector stakeholder institutions invited for the workshop, 22 water sector decision makers from 11 institutions participated (Figure 1).

In this task, all participants were initially briefed about the current setting of water sector and then were asked to participate in an activity to develop the targeted multi criteria water allocation decision making models. The participants were requested to assign a priority weight for the water user organisations to distribute a limited quantity of water. In this, any spatial or temporal variability of the available water was ignored. The quality of this water was also assumed as good. Hence this task could be considered as an elementary case of decision making by considering only the influence and the magnitude of the service delivery activity of a particular user.

\subsection{The Approach}

This evaluation used a combination of multi criteria modelling [19], [20] and order of magnitude computations based on present water sector setting to compute and compare the priority weights assigned to each water user (Figure 2). Most commonly used Analytical Hierarchy Process (AHP) developed by Saaty [21], [22] was selected as the Multi Criteria Decision Analysis (MCDA) Model for the computation of weights.

\section{Methodology}

The 20 water user institutions included, National Water Supply and Drainage Board(NWSDB), Department of National Community Water Supply (DNCWS), Mahaweli Authority of Sri Lanka (MASL), Central Environmental Authority (CEA), Irrigation Department (ID), Department of Agriculture (DA), Water Resources Board (WRB), Department of Agricultural Diversification and Settlement Authority (DADA), Disaster Management Center (DMC), Board of Investment (BOI), Ceylon Electricity Board (CEB), National Aquatic Resources Research and Development Agency (NARRDA), Coast Conservation Department (CCD), National Planning Department (NPD), Sri Lanka Land Development Corporation
(SLLDC), Department Forest Conservation (DFC), Geological Survey and Mines Bureau (GSMB), Dept of Agrarian Service (DAS), Local Governments (LG) and the Public Utility Commission of Sri Lanka (PUCSL). Each stakeholder representative was asked to assign a numerical value between 0 and 1000 to indicate the priority to given to any particular agency.

As the first step, each participant assigned a single preferential indicator value for water allocation to each agency. In the second step each participant assigned priority values by independently considering the influence and magnitude and each service delivery activity which is entrusted to a water user institution. In the first step, assigning of a single cumulative priority value for each agency was facilitated by enabling each participant to work within an indicator range 0-1000. The variation of priority values that had been assigned by each participant to the 22 water user institutions showed a very wide variation which clearly reflected the differences in their opinion. However, it is important to note that the diverse and conflicting interests among stakeholders is very common and that there is no unique method to obtain stakeholder cooperation for an agreed response [19], [23]. In the absence of a set procedure for decision making at a stakeholder meeting, the present work considered simple average of responses given to any institution as the priority indicator assigned by the participants for that institution (Figure 3). This consideration, which assumed a near equal status of expertise and understanding among the participants about the water sector users and their operations, was considered as the most rational approximation under the setting of this case study.

The second step intended to investigate the decision making by utilizing the criteria associated with the achievement of objective. Decision making with respect to decision alternatives becomes simpler when an objective is divided into criteria. There are many criteria for water allocation depending on a situation. Among the many criteria, the economic and ecological benefits also take a significant role [24], [25]. A discussion among water professionals engaged in water allocation between different water users revealed that most frequently considered criteria are the nature of use such as essential or non-essential, the number of users, the 
spatial coverage, and consumptive or nonconsumptive use. In the present work, in order to serve the study objective, participating stakeholders were requested to consider all factors such as economy, environment, type of use etc., under the category of "Influence" and the number of users together with the greatness of the coverage as "Magnitude". Hence the second AHP model was developed with these two criteria. In this task, the participants assigned priority values to each water user institution by considering one criterion at a time. Assigning of priority was based on a five-point scale ranging from 0 to 4 where 0 was the lowest while 4 was the highest value given to a particular institution.

\subsection{Plain AHP model}

Two AHP model development followed the descriptions in Saaty [21]-[23], [26] to assign water allocation weights to the 20 water user institutions. The plain AHP model (Figure 4) aimed to compute water allocation priorities by using a single combined criterion while the two criteria AHP model attempted to achieve the same objective using the influence and magnitude of service delivery as criteria.

In the Plain HP model, the average priority indicators assigned by the water user stakeholders (Figure 3), were taken in pairs to carry out the pairwise comparison of all water user institutions. Pairwise comparison for each element was based on an element of the upper hierarchy which is the evaluation standard. In this case the pairwise (comparison) matrix consists of $20 \times 20$ elements. Then the eigen vector and the eigen value of the pairwise comparison matrix were computed. Computed eigenvector gives the relative ranking of the water users. In this computation, an important step is to evaluate the acceptability of the relative priority calculated for each water user. In order to evaluate the acceptability of the pairwise comparison, consistency ratio $(C R)$ should be calculated and it should be less than 0.1 for a matrix greater than or equal to $5 \times 5$ [27]. Therefore, the weighted sum vector and consistency vector were developed using Equation 1 and Equation 2, in order to determine the Lambda value for consistency ratio calculation applying Equation 3. Next, the Consistency Ratio $(C R)$ was calculated using the Consistency Index $(C I)$ and Random Inconsistency Index $(R I)$ as explained in Equation 3.
The computed Lambda and CI values of the plain AHP model are 20.37 and 0.0195 respectively. Accordingly, $R I_{20}$ is 1.58 [28]. The model resulted in a $C R$ value of 0.012 with less than 0.1 showing that the resulted relative priority indicators have fulfilled the consistency requirement of AHP. Weights are in Table 2.

$$
\begin{aligned}
{\left[\begin{array}{c}
\text { Weighted } \\
\text { Sum Vector }
\end{array}\right]=} & {\left[\begin{array}{c}
\text { Pairwise } \\
\text { Matrix }
\end{array}\right] } \\
& \times\left[\begin{array}{c}
\text { Consistency } \\
\text { Matrix }
\end{array}\right] \\
{\left[\begin{array}{c}
\text { Consistency } \\
\text { Vector }
\end{array}\right]=} & \frac{\left[\begin{array}{c}
\text { Weighted } \\
\text { Sum Vector }
\end{array}\right]}{\left[\begin{array}{c}
\text { Consistency } \\
\text { Matrix }
\end{array}\right]} \\
C R= & \frac{C I}{R I_{n}}
\end{aligned}
$$

Where,

$$
C I=\frac{L a m b d a-n}{n-1}
$$

$n$ is number of alternatives and Lambda is average of elements in Consistency vector

\subsection{Two Criteria AHP Model}

\subsubsection{User given Indicators}

The Two Criteria AHP model schematic is given in Figure 5. The wide variation of participant responses and their average with respect to the perception on magnitude of water service delivery by each water user institution is shown in Figure 6. The variation with respect to the perception on the influence of service delivery activities is shown in Figure 7. Using the same assumption as in the case of the plain AHP model, the average preferences shown by participating stakeholders were converted to the Saaty scale for the construction of pairwise comparison matrix of the two criteria AHP model.

\subsubsection{Weights of Alternatives}

Following the same procedure, as in the case of Plain AHP model, the consistency matrix, weighted sum vector, and consistency vectors were developed by using the normalized pairwise comparison matrix. In case of the magnitude, a Lambda value of 20.38 resulted in a $C R$ value of 0.012 which ensured that the ranking and respective relative priority weights for each water user agency for magnitude have fulfilled the consistency criteria of AHP. In case of the influence, the computations using average of expert 
indicator selections resulted in a $C R$ value of 0.0093 which also resulted in a set of relative priority weights fulfilling the consistency criteria.

\subsubsection{Weights for Criteria}

After considering the simplicity required for the evaluation of decision-making capability by a group of experts, the magnitude and influence of water sector service delivery were taken as the only criteria for the model.

Discussions among water management experts revealed that the preferred weightages for magnitude and influence are approximately 0.4 and 0.6, respectively. However, when observing data of participant responses with respect to magnitude and influence of each agency, the indication is their inclination to give equal weightage. In order to consider the uncertainty associated with the relative importance between magnitude and influence, the present work selected three combinations of the weights to evaluate the sensitivity of the two criteria AHP model. In this context the variation of each criteria weight between 0.25 and 0.75 was investigated and the selected combinations are shown in Table 1. The priority weights for the considered modelling options are in Table 2.

\section{Table 1 - Combination of Weights for Two Criteria AHP Model Evaluation}

\begin{tabular}{|l|l|l|}
\hline \multirow{2}{*}{ Case \# } & \multicolumn{2}{|l|}{ Relative Importance } \\
\cline { 2 - 3 } & Magnitude & Influence \\
\hline i & $75 \%$ & $25 \%$ \\
\hline ii & $50 \%$ & $50 \%$ \\
\hline iii & $25 \%$ & $75 \%$ \\
\hline
\end{tabular}

\section{Results and Discussion}

\subsection{Models and Stakeholder Preference}

Comparison of water allocation priority weight for each agency was conducted by comparing five outputs from three different methods. They were the outputs from, 1) plain AHP model 2) Two criteria model - Case i, Case ii and Case iii, and 3) normalized preferential indicator model which used normalized the varying priority assigned by participating water experts.

Priority rank assigned to each water user showed variations depending on the modelling option (Figure 8). In order to ensure easy understanding, the priority score option of an institution indicated in Figure 8 was computed by using the number of stakeholder institutions plus 1 minus the priority rank of that institution. Priority weights by each model expresses that the normalized preferential indicator model has assigned near equal weights while the others show a difference that reflects a clear variation of priority. Ranks by water users in each model showed that ID and NWSDB, had always received the highest positions. Though it could be seen that, depending on the model, ranks of ID and NWSDB had interchanged their positions, MASL had received the third priority for all modelling options. Graphical representation of the variation of priority weights is in Figure 9 while the numerical values are in Table 2.

In order to arrive at a water allocation model, the present work carried out the averaging of widely varying stakeholder opinion together with the exploration of a few simple yet different modelling assumptions. The results have demonstrated that stakeholder decisions based on prior knowledge, experience and judgement can be modelled in different ways and achieve theoretically consistent solutions. Literature has examples showing that results from MCDA models can be consistent but may not be unique and hence such outputs require substantiation with other supporting information for rational decision making [29], [30]. Therefore, the present study shows that it is very important to carefully assess the wide variation of stakeholder judgement together with the models used for water allocation. In this study, user preferences from the key water institutions have a tendency to show a bias towards the parent institutions. Hence this case study is an example to avoid water allocations based only on stakeholder opinion. It is also needed to understand that there is a requirement to verify the applicability of a selected method amidst available information.

\subsection{Order of Magnitude of Performance}

Water resource allocation to each stakeholder by using a model requires a good assessment of available water resources, and water demands of each stakeholder. An evaluation of documentation on available water resources revealed that the annual volume of available water in Sri Lanka is approximately 42 billion cubic meters [2], [31]-[33]. The next requirement for allocation is the determination of water use or water demand by each stakeholder agency. Annual water usage of ID, 
MASL and NWSDB were calculated based on their coverage area, average monthly usage and practice norms. ID releases water to an approximate cultivation area of $3,097 \mathrm{~km}^{2}$ with an average annual irrigation duty of $1.24 \mathrm{~m}$. A district wise calculation indicated that the approximate average annual water use is 7 , 491, 966, $432.0 \mathrm{~m}^{3}$. According to corporate plan information of NWSDB [34], the approximate water production for 2020 would be $710,049,268.1 \mathrm{~m}^{3}$. MASL provides water for irrigation to a cultivation area of $192,006 \mathrm{Ha}$ and for hydro-power generation to generate 2,413.58 GWh of electricity annually. As per published cropping calendars, the water requirement per season is 2,183,900,000 $\mathrm{m}^{3}$. Water releases by MASL during Maha season from October to March of a given year is approximately $65 \%$ of the computed seasonal requirement, while the same for Yala season from April to September is 100\% [35], [36]. Accordingly, the approximate annual water requirement of MASL amounted to 3, 603, $435,000 \mathrm{~m}^{3}$. The water use by other sectoral users could not be captured by the information in literature. Hence, water requirements of these three major water users were utilized to carry out the best possible comparison of five water allocation model options in order to achieve the objective of present study.

\subsection{Comparative Evaluation}

In this comparative and order of magnitude assessment, annual water requirements were first allocated by using the derived priority weights of each model. Then, commencing from the institution having the top rank, the allocated and required water were matched to make reallocations. Since water use data was available for only the three highest ranked stakeholders, the reallocation in this work focused to match their requirements. Hence the results presented in Figure 10 do not reflect the final water allocation result after considering water demands of all stakeholders. Reallocation results of ID, NWSDB and MASL revealed sufficient outputs to achieve the objective of current study.

Reallocation of available excess water to other water users showed that all models except the normalized user indicator model could satisfy the requirements of NWSDB and MASL. The NWSDB over allocation was first redistributed using model weights for other institutions. Then, in the same manner, the MASL over allocation was also redistributed. The water allocation output at this stage reflected that the
ID requirements could be matched by reallocating water which had been prioritized for other users. This could not be pursued further because annual requirements of other agencies were not available. However, by comparing the water requirements of NWSDB, MASL and ID, it could be noted that there were high priority allocations to some of the agencies and they could be reallocated only when their real requirements are known. The normalized user indicator model which does not contain a consistency check, performed different to the other modelling options. Hence it is felt that this option would not be a rational solution to consider water allocation.

Results of water allocation model comparison pointed to several key factors. At first, water availability must be known to a fair accuracy to prioritize water using the model computed weights. Then water requirements of each stakeholder must be available for step by step water reallocation. Once the model inputs and outputs are known, then only the models can be compared, calibrated and verified for rational water management. This clearly shows that unless water availability and water demands are assessed to an acceptable accuracy, the stakeholder discussions based on judgement would not arrive at acceptable water allocations. The results of this study also lead to the opinion that the combined use of a "transparent water availability and demand assessment mechanism" supported by a verified model developed through stakeholder discussion would be the most rational option for better water management. Therefore it is very important for Sri Lanka to urgently establish a comprehensive water policy, supporting tools and regulations for rational allocation of water among competing water users.

\section{Conclusions and Recommendations}

- The present study demonstrated that MCDA water allocation models having consistent model parameters can be satisfactorily developed by using stakeholder judgement with regards to water allocation of priority.

- Stakeholder based water allocations must carefully evaluate the wide variation of judgements, modelling uncertainties and assumptions when agreeing on an appropriate model. 
- Wide variation of perception demonstrated by the key water stakeholders demonstrate that even if the average opinion is considered, there is a wide variation of modelling options and hence water allocation based on stakeholder opinion alone is not satisfactory.

- The normalized preferential indicator model which differed from the conventional multicriteria model options must only be used with careful evaluations.
- Any attempts to use stakeholder consultations for water allocation among competing water users must be well supported with transparent and verified water availability and demand assessments.

- The present study, by clearly demonstrating that stakeholder judgement based water allocation without sound information does not lead to acceptable water allocation, presents the importance of having a comprehensive water policy, rules and regulations.

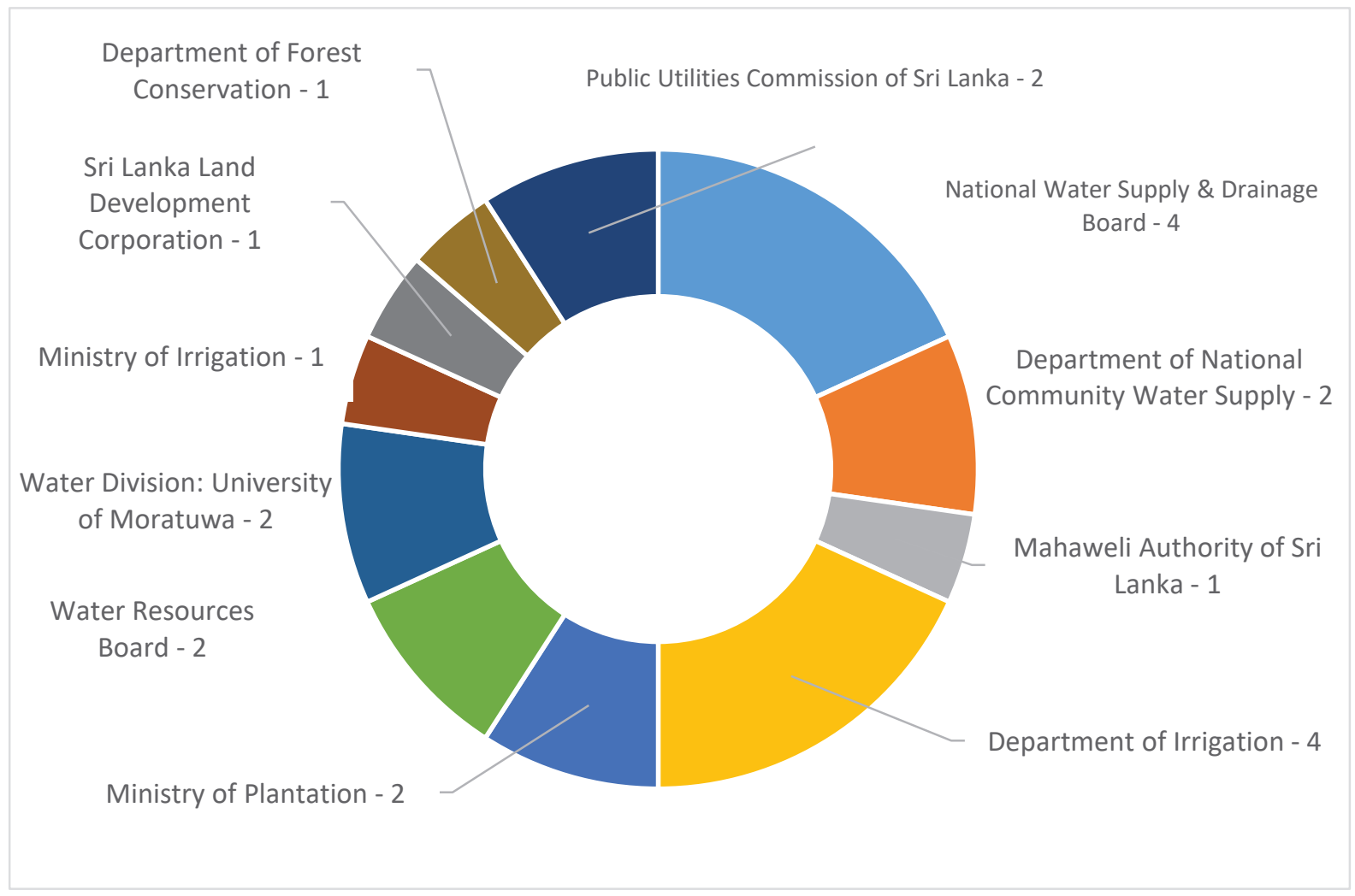

Figure 1 - Workshop Participant Distribution (Institution and the Number) 


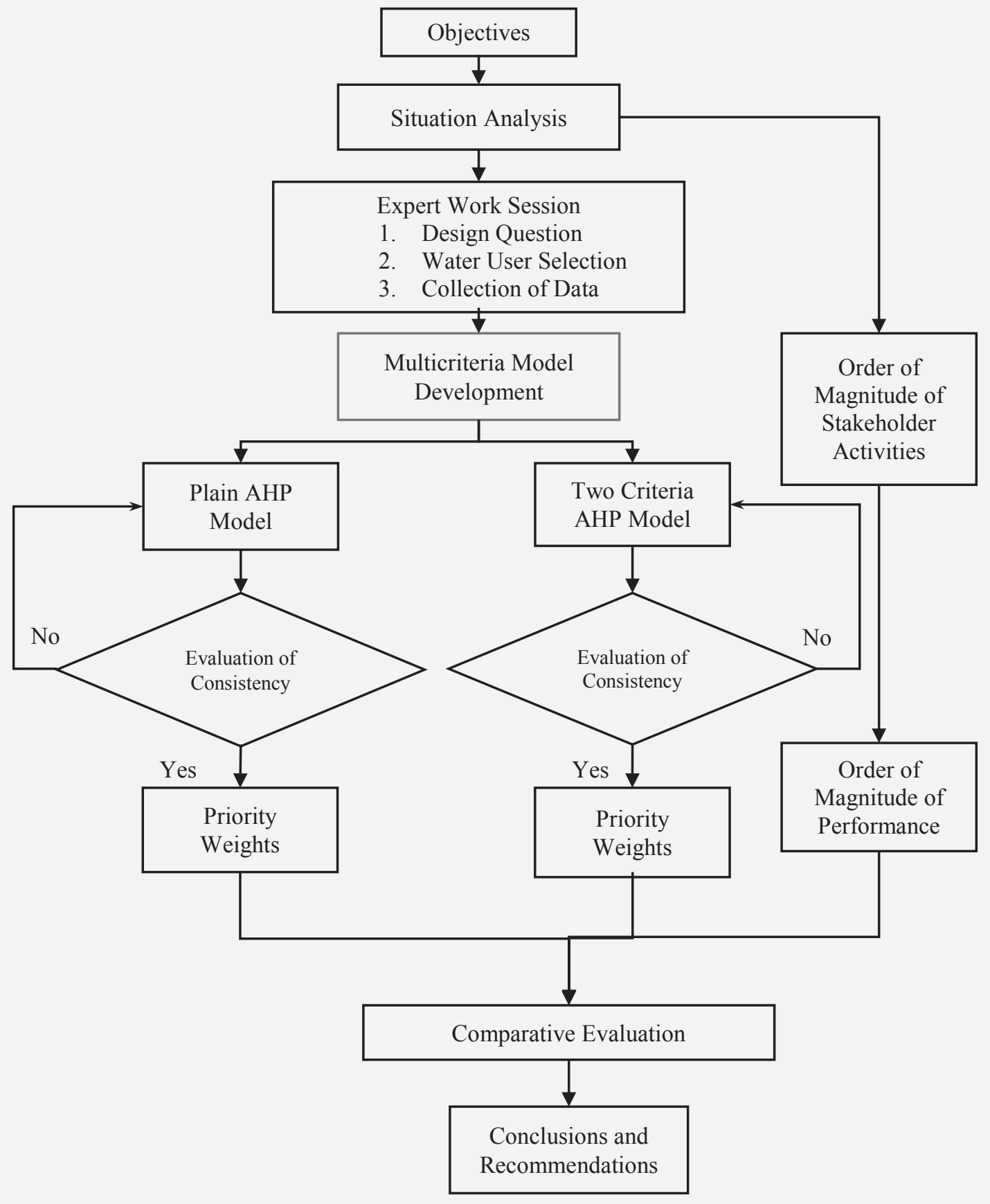

Figure 2 - Methodology Flow Chart 


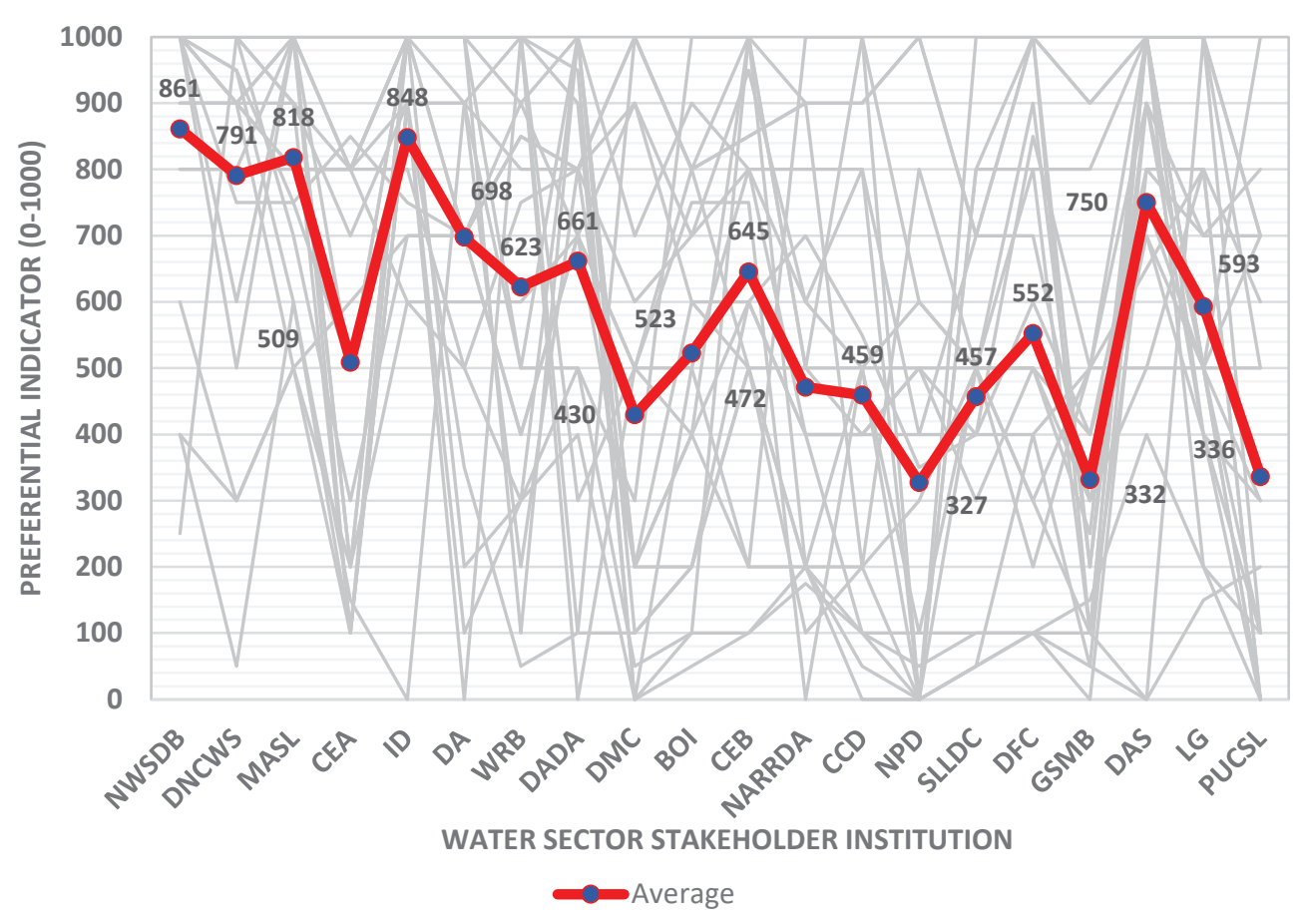

Figure 3 - Stakeholder Responses (Grey) and the Average(Red) - Plain AHP

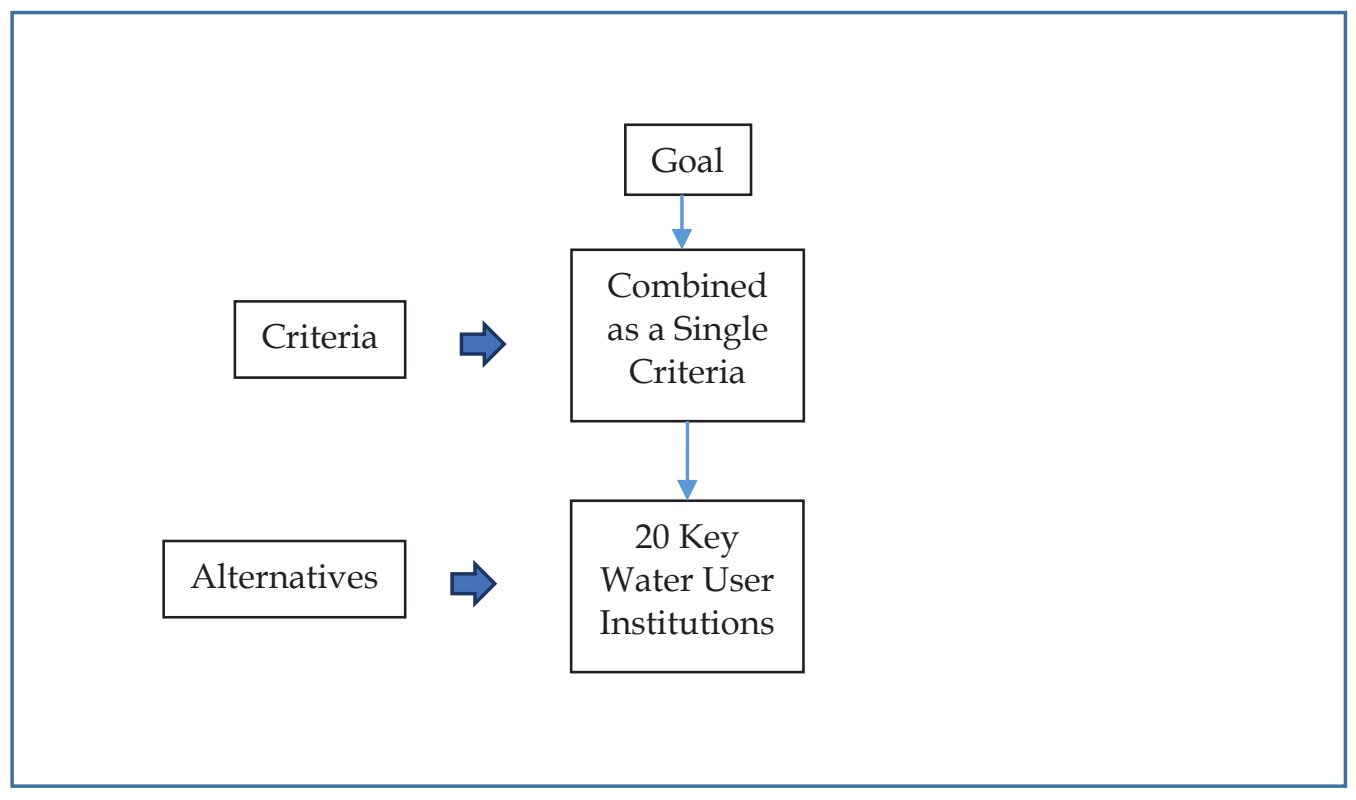

Figure 4 - The Plain AHP Model 


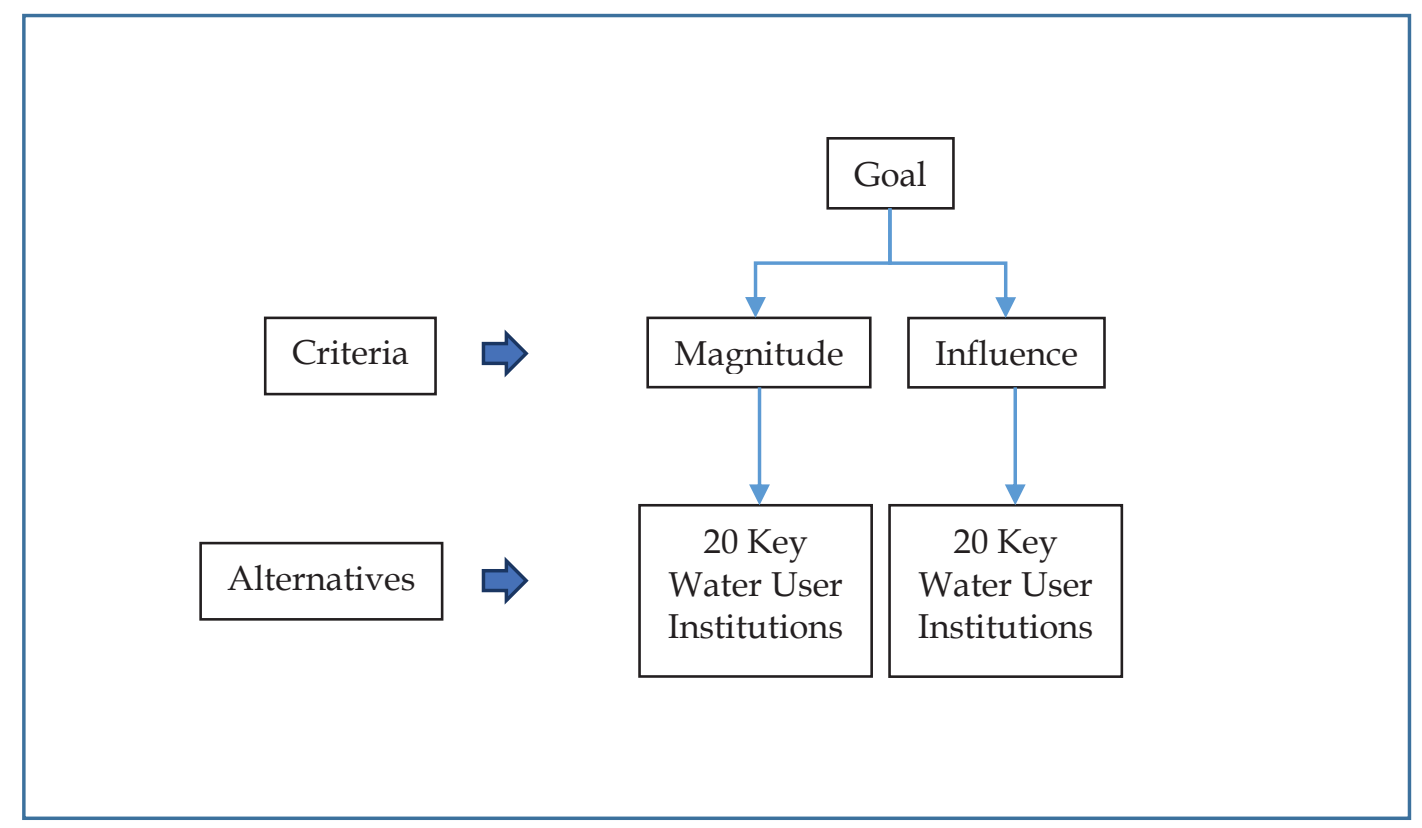

Figure 5 - The Two Criteria AHP Model

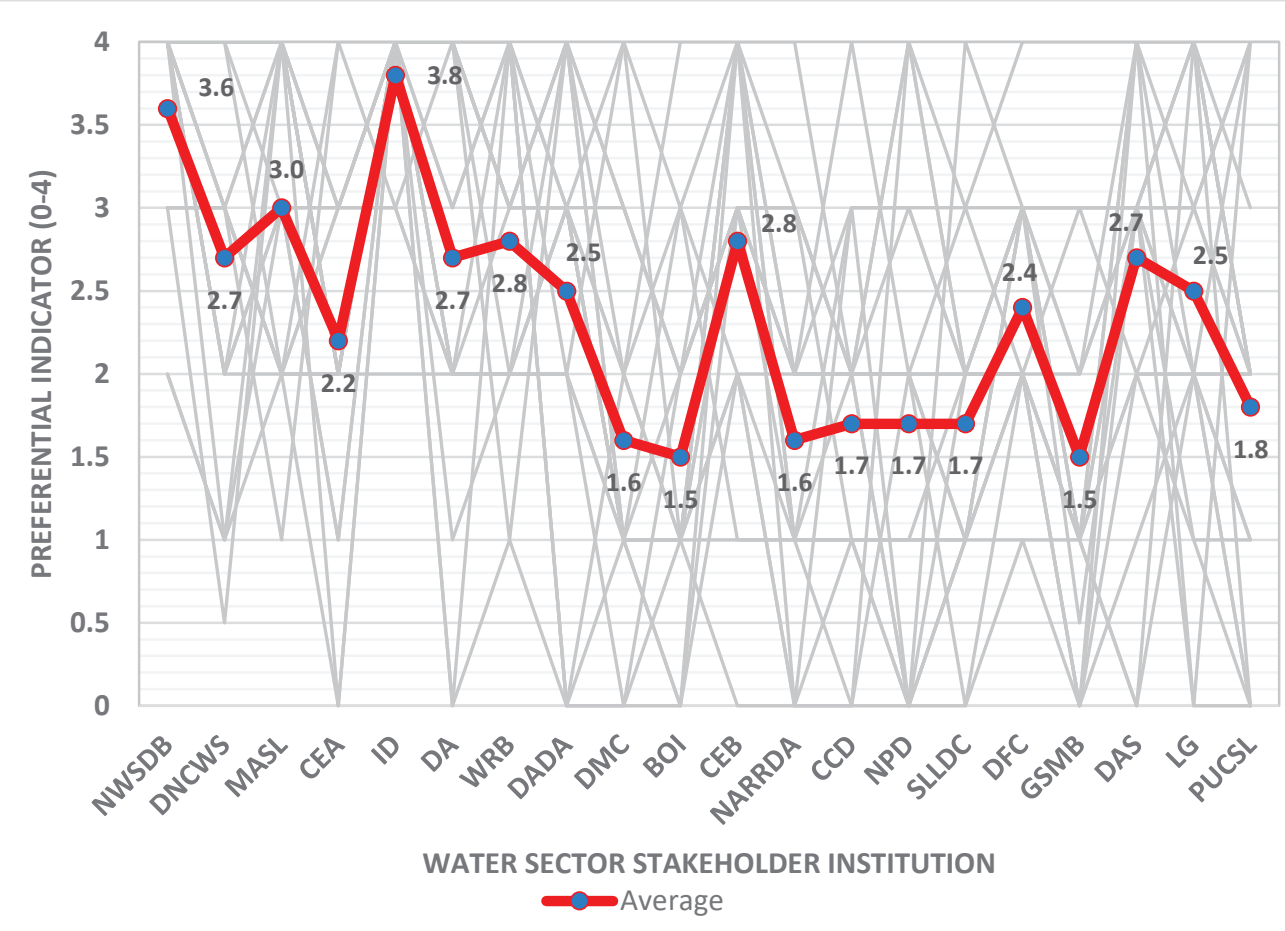

Figure 6 - Stakeholder Responses(Grey) and the Average (Red) - Magnitude 


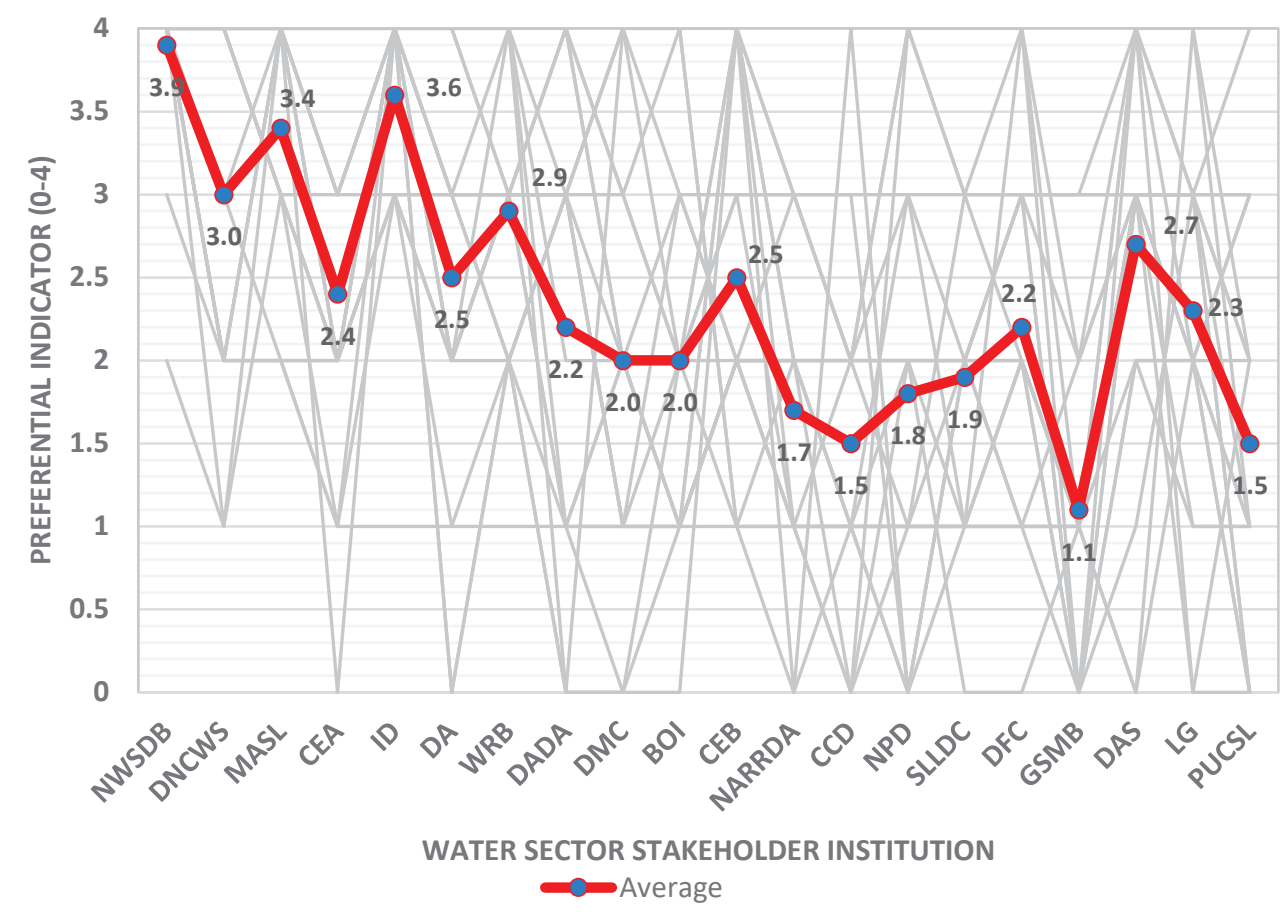

Figure 7 - Stakeholder Responses and the Average - Influence

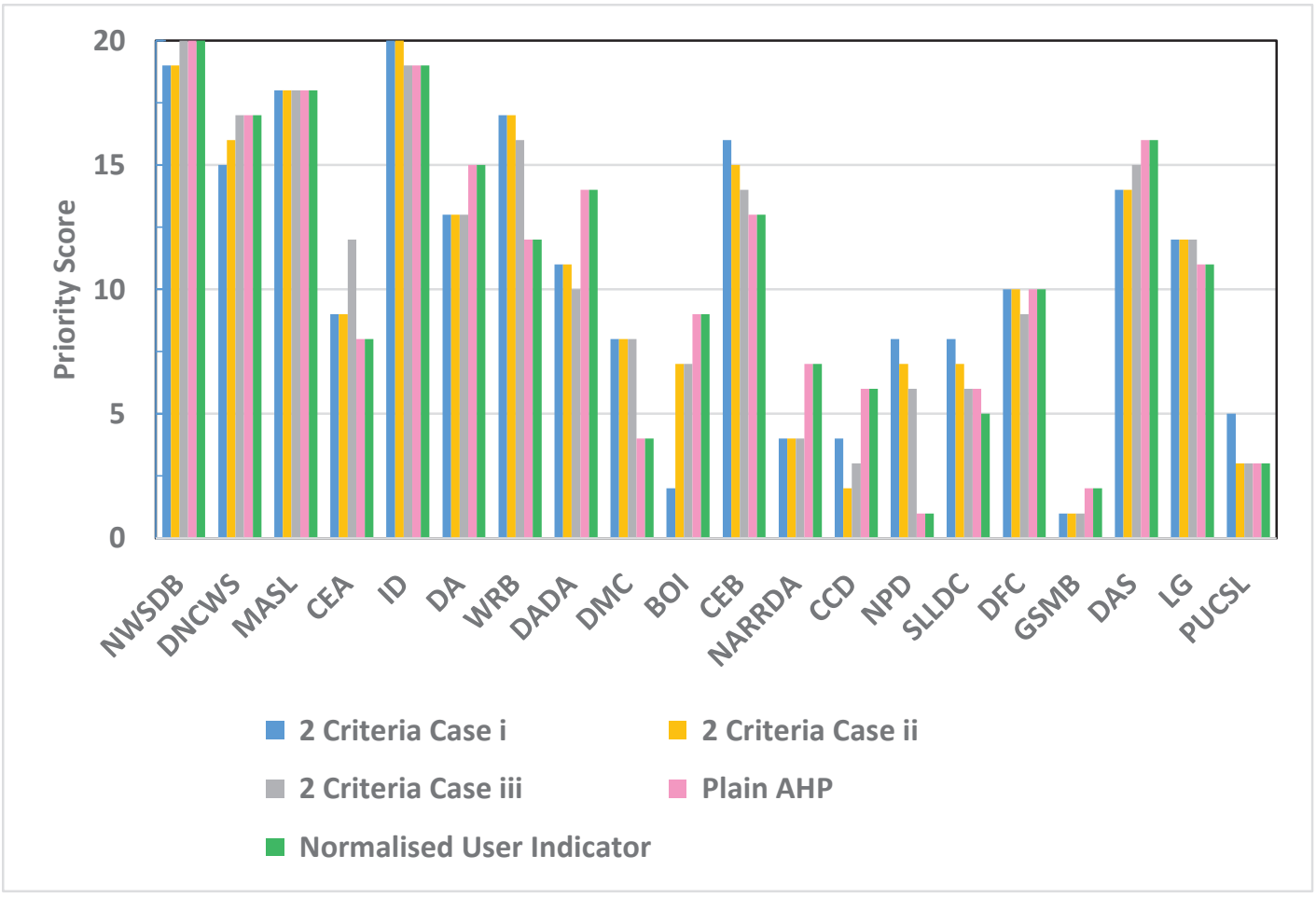

Figure 8 - Comparison of Water User Priority Score under Each Modelling Option 


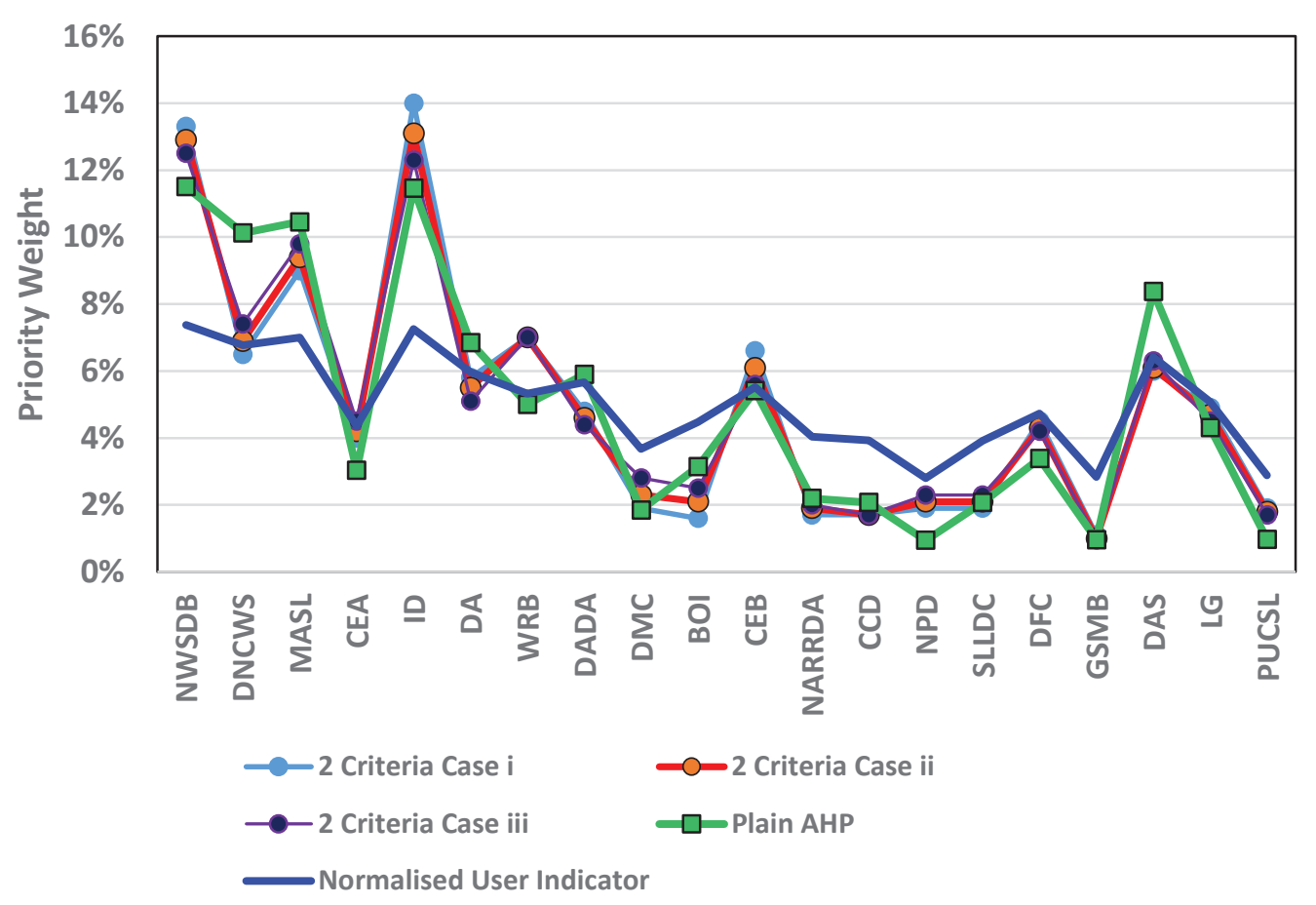

Figure 9 - Model Options and Water User Priority Comparison

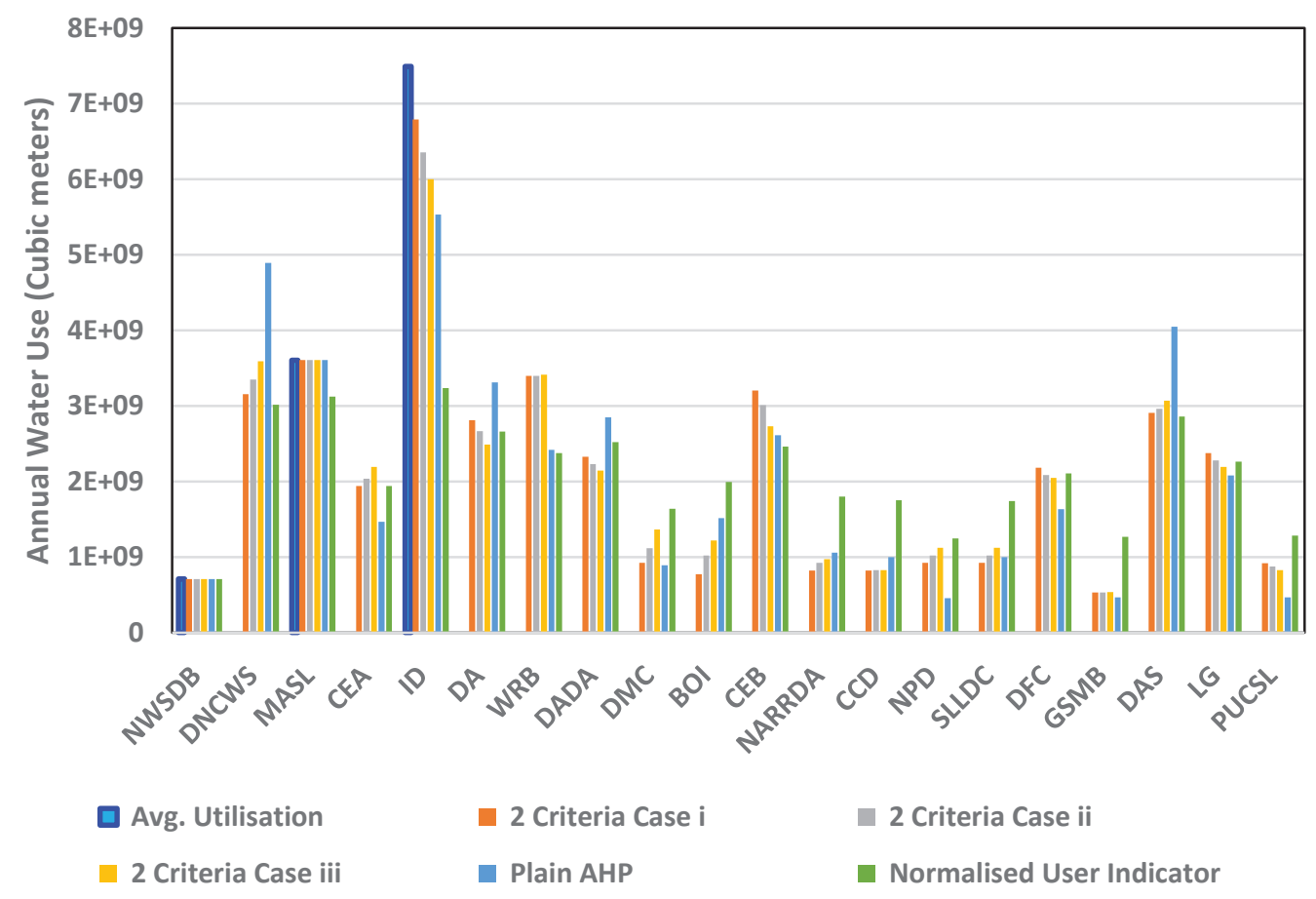

Figure 10 - Comparison of Model Capability using Available Water User Data 
Table 2 - Model Options and Water User Priority Comparison

\begin{tabular}{|c|c|c|c|c|c|}
\hline \multirow[b]{2}{*}{ Water User } & \multicolumn{3}{|c|}{ Two Criteria Model } & \multirow{2}{*}{$\begin{array}{c}\text { Plain AHP } \\
\text { Model }\end{array}$} & \multirow{2}{*}{$\begin{array}{c}\text { Normalised } \\
\text { User Indicator } \\
\text { Model }\end{array}$} \\
\hline & $\begin{array}{l}2 \text { Criteria } \\
\text { Case } \mathrm{i}\end{array}$ & $\begin{array}{c}2 \text { Criteria } \\
\text { Case ii }\end{array}$ & $\begin{array}{c}2 \text { Criteria } \\
\text { Case iii }\end{array}$ & & \\
\hline NWSDB & $13.30 \%$ & $12.90 \%$ & $12.50 \%$ & $11.51 \%$ & $7.37 \%$ \\
\hline DNCWS & $6.50 \%$ & $6.90 \%$ & $7.40 \%$ & $10.12 \%$ & $6.77 \%$ \\
\hline MASL & $9.00 \%$ & $9.40 \%$ & $9.80 \%$ & $10.45 \%$ & $7.00 \%$ \\
\hline CEA & $4.00 \%$ & $4.20 \%$ & $4.50 \%$ & $3.03 \%$ & $4.36 \%$ \\
\hline ID & $14.00 \%$ & $13.10 \%$ & $12.30 \%$ & $11.46 \%$ & $7.25 \%$ \\
\hline DA & $5.80 \%$ & $5.50 \%$ & $5.10 \%$ & $6.85 \%$ & $5.97 \%$ \\
\hline WRB & $7.00 \%$ & $7.00 \%$ & $7.00 \%$ & $5.00 \%$ & $5.33 \%$ \\
\hline DADA & $4.80 \%$ & $4.60 \%$ & $4.40 \%$ & $5.90 \%$ & $5.66 \%$ \\
\hline DMC & $1.90 \%$ & $2.30 \%$ & $2.80 \%$ & $1.85 \%$ & $3.68 \%$ \\
\hline BOI & $1.60 \%$ & $2.10 \%$ & $2.50 \%$ & $3.14 \%$ & $4.47 \%$ \\
\hline CEB & $6.60 \%$ & $6.20 \%$ & $5.60 \%$ & $5.41 \%$ & $5.52 \%$ \\
\hline NARRDA & $1.70 \%$ & $1.90 \%$ & $2.00 \%$ & $2.19 \%$ & $4.04 \%$ \\
\hline CCD & $1.70 \%$ & $1.70 \%$ & $1.70 \%$ & $2.07 \%$ & $3.93 \%$ \\
\hline NPD & $1.90 \%$ & $2.10 \%$ & $2.30 \%$ & $0.94 \%$ & $2.80 \%$ \\
\hline SLLDC & $1.90 \%$ & $2.10 \%$ & $2.30 \%$ & $2.07 \%$ & $3.91 \%$ \\
\hline DFC & $4.50 \%$ & $4.30 \%$ & $4.20 \%$ & $3.38 \%$ & $4.73 \%$ \\
\hline GSMB & $1.10 \%$ & $1.10 \%$ & $1.10 \%$ & $0.96 \%$ & $2.84 \%$ \\
\hline DAS & $6.00 \%$ & $6.10 \%$ & $6.30 \%$ & $8.38 \%$ & $6.42 \%$ \\
\hline LG & $4.90 \%$ & $4.70 \%$ & $4.50 \%$ & $4.31 \%$ & $5.08 \%$ \\
\hline PUCSL & $1.89 \%$ & $1.80 \%$ & $1.70 \%$ & $0.97 \%$ & $2.88 \%$ \\
\hline
\end{tabular}

\section{References}

1. Samad, M., Aheeyar, M., Royo-Olid, J., and Arulingam, I., "The Political and Institutional Context of the Water Sector in Sri Lanka an Overview," Luxembourg: Publications Office of the European Union, 2017.

2. Department of National Planning Sri Lanka, "Public Investment Programme 2017-2020," 2017.

3. Irrigation Management Division, "Integrated Management of Irrigation Settlements (INMAS) to Develop Water Management Plans," Ministry of Mahaweli Development, 2020. [Online]. Available at: http://www.irrigationmin.gov.lk/irrigation -management-

division/index.html\#: :text=Established in 1984\%2C Irrigation Management,area under inter-provincial irrigation.

4. Parliament of Sri Lanka, Mahaweli Authority of Sri Lanka (Act 23) of 1979, no. 35. 1979, pp. 177-191.
5. Sirisena, M., Amaraweera, M., and Jayarathna, A., "Annual Performance Report \& Accounts - Ministry of Mahaweli Development and Environment," 2017.

6. Athukorala, K., "Collective Action for Protection of Water Rights: The Case of Thuruwila, Sri Lanka," in Eleventh Conference of the International Association for the Study of Common Property, 2006.

7. Aheeyar, M. M. M., Nanayakkara, V. K., and Bandara, M. A. C., "Allocation of Water among Different Water-use Sectors in Sri Lanka: Lessons of Experience," 2008.

8. Kamaladasa, B., "Internal Working Paper of Water Management Branch," 2018.

9. Wickramasinghe, K., "Thambuttegama Farmers Losing their Calm before the 'Storm,'” 2018.

10. Kamaladasa, B., "Personnel Communication with Divisional Irrigation Engineer Rajangana and Director of Irrigation in Anuradhapura," 2020. 
11. Hamseen, M. H. M., and Sivakumar, S. S., "Conflict Resolution in Multiple Water User in North Central Region of Sri Lanka," Int. J. Sci. Eng. Res., Vol. 8, no. 10, 2018.

12. Ratnasiri, J., "Water for Jaffna Groundwater, Sea Water, Lagoon Water or Pristine Knuckles Water?," The Island, 2019. [Online]. Available: http://www.island.lk/index.php?page_cat= article-details\&page $=$ articledetails\&code_title=212652. [Accessed: 20Jun-2020].

13. ADB, “Democratic Socialist Republic of Sri Lanka : Jaffna and Kilinochchi Water Supply and Sanitation Project -37378," 2010.

14. Ponrajah, A. J. P., "Design of Irrigation Headworks for Small Catchments," Department of Irrigation, Colombo Sri Lanka, 1984.

15. Manthrithilake, H., and Liyanagama, B. S., "Simulation Model for Participatory Decision Making: Water Allocation Policy Implementation in Sri Lanka," Water Int., Vol. 37, no. 4, pp. 478-491, 2012.

16. ADB, "Towards Effective Water Pollicy in the Asian and Pacific Region - Volume 1," in The Regional Consultation Workshop Towards a Policy for Water Resources Development and Management in the Asian and Pacific Region, 1996.

17. ADB, "Towards Effective Water Pollicy in the Asian and Pacific Region - Volume 3," in The Regional Consultation Workshop Towards a Policy for Water Resources Development and Management in the Asian and Pacific Region, 1996.

18. Ministry of Agriculture Rural Economic Affairs Irrigation and Fisheries and Aquatic Resources Development, "Sri LankaOverarching Agricultural Policy Draft," no. August, 2019.

19. Soltani, A., Hewage, K., Reza, B., and Sadiq, R., "Multiple Stakeholders in Multi-Criteria Decision-Making in the Context of Municipal Solid Waste Management: A Review," Waste Manag., Vol. 35, pp. 318-328, 2015.

20. Jhariya, D. C., Kumar, T., and Pandey, H. K., Watershed Prioritization based on Soil and Water Hazard Model using Remote Sensing, Geographical Information System and MultiCriteria Decision Analysis Approach, Vol. 35, no. 2. Taylor \& Francis, 2020.

21. Saaty, T. L., "Decision Making with the Analytic Hierarchy Process," Int. J. Serv. Sci., Vol. 1, no. 1, p. 83, 2008.
22. Saaty, T. L., "How to Make a Decision: The Analytic Hierarchy Process," Eur. J. Oper. Res., Vol. 48, no. 1, pp. 9-26, 1990.

23. De Feo, G., and De Gisi, S., "Using an Innovative Criteria Weighting Tool for Stakeholders Involvement to Rank MSW Facility Sites with the AHP," Waste Manag., Vol. 30, no. 11, pp. 2370-2382, 2010.

24. Cetinkaya, C. P., and Gunacti, M. C., "MultiCriteria Analysis of Water Allocation Scenarios in a Water Scarce Basin," Water Resour. Manag., Vol. 32, no. 8, pp. 2867-2884, 2018.

25. Messner, F., Zwirner, O., and Karkuschke, M., "Participation in Multi-Criteria Decision Support for the Resolution of a Water Allocation Problem in the Spree River Basin," Land use policy, Vol. 23, no. 1, pp. 6375, 2006.

26. Saaty, R. W., "The Analytic Hierarchy Process-What it is and How it is used," Math. Model., Vol. 9, no. 3-5, pp. 161-176, 1987.

27. Jovanovic, B., Filipovic, J., and Bakic, V., "Prioritization of Manufacturing Sectors in Serbia for Energy Management Improvement - AHP Method," Energy Convers. Manag., pp. 225-235, 2015.

28. Saaty, T. L., and Tran, L. T., "On the Invalidity of Fuzzifying Numerical Judgments in the Analytic Hierarchy Process," Math. Comput. Model., Vol. 46, no. 7-8, pp. 962-975, 2007.

29. Benítez, J., Carpitella, S., Certa, A., and Izquierdo, J., "Characterization of the Consistent Completion of Analytic Hierarchy Process Comparison Matrices using Graph Theory," J. Multi-Criteria Decis. Anal., Vol. 26, no. 1-2, pp. 3-15, 2019.

30. Kumari, T. K. N. K., "Multicriteria Decision Modelling for Management of Water Supply System in the Piliyandala-Kesbewa Water Supply System, Colombo District, Sri Lanka," University of Moratuwa, 2015.

31. Imbulana, K. A. U. S., Wijesekera, N. T. S., Neupane, B. R., Aheeyar, M. M. M., and Nanayakkara, V. K., Eds., Sri Lanka Water Development Report: 2010. UNESCO \& Ministry of Irrigation and Water Resources Management, 2010.

32. Price Waterhouse Coopers(PWC), "Water Sector of Sri Lanka (Embassy of the Kingdom of the Netherlands)," 2014. 
33. Arumugum, S., Water Resources of Ceylon its Utilisation and Development. Water Resources Board, Sri Lanka, 1969.

34. NWSDB, "National Water Supply \& Drainage Board, Home Page," 2019. [Online]. Available:

www.waterboard.lk/web/index.php?lang=e n. [Accessed: 31-Jan-2019].

35. Ministry of Mahaweli Development, "Mahaweli Authority of Sri Lanka." [Online]. Available: mahaweli.gov.lk. [Accessed: 12-May-2020].

36. Mahaweli Authority of Sri Lanka, "SocioEconomic Statistics 2018." p. 170, 2018. 